Published in final edited form as:

Immunol Lett. 2013 ; 155(0): 40-42. doi:10.1016/j.imlet.2013.09.014.

\title{
Chimeric antigen receptors (CARs) from Bench-to-Bedside
}

\author{
Barbara Savoldo ${ }^{a, b}$ and Gianpietro Dotti ${ }^{a, c, d,}$, \\ aCenter for Cell and Gene Therapy, Baylor College of Medicine, The Methodist Hospital and \\ Texas Children's Hospital, Houston, TX 77030, USA \\ bDepartment of Pediatrics, Texas Children's Hospital, Houston, TX 77030, USA \\ 'Department of Medicine, Baylor College of Medicine, Houston, TX 77030, USA \\ ${ }^{d}$ Department of Immunology, Baylor College of Medicine, Houston, TX 77030, USA
}

\begin{abstract}
Chimeric antigen receptors (CARs) combine the antigen specificity of an antibody with the biologic properties of T lymphocytes. While the concept has been developed more than 20 years ago, only in recent years the clinical application of this approach has produced remarkable objective clinical responses. In this brief review, we outline some specific aspects that have led to antitumor responses in cancer patients.
\end{abstract}

\section{Introduction}

Gene transfer of aßT-cell-receptor (TCRs) and chimeric antigen receptors (CARs) can reproducibly and efficiently redirect the antigen specificity of polyclonal T lymphocytes, thus overcoming the tedious process and frequent failures of strategies based on the ex vivo reactivation and expansion of T-cell precursors with native antitumor activity.

CARs are composed of a specific antigen binding moiety, obtained from the variable regions of a monoclonal antibody, linked together to form a single chain antibody ( $\mathrm{scFv}$ ), and of signaling components derived from the $\zeta$ chain of the TCR/CD3 complex and from costimulatory molecules ${ }^{1 ; 2} \mathrm{~T}$ lymphocytes expressing a CAR bind to the specific antigen expressed on target cells through the $\mathrm{scFv}$ segment and then activate their lytic and costimulatory pathways promoting cytotoxic activity and cell expansion (Fig. 1). The immediate obvious advantage of this technology is the MHC unrestriction of the cytotoxic activity mediated through the CAR component as the antigen recognition is antibody mediated $^{1}$. This approach licenses $\mathrm{T}$ cells to recognize a great variety of tumor cell types as reviewed elsewhere ${ }^{3 ; 4}$ Here we will briefly summarize some results obtained so far from clinical trials and indicate some future directions.

\section{Methodologies to express CARs and to expand T cells ex vivo}

Gamma retrovirus and lentiviruses are frequently used to insert CARs in T lymphocytes for clinical applications ${ }^{5-10}$. Such vectors have the benefit of efficiently infect T lymphocytes,

\footnotetext{
(C) 2013 Elsevier B.V. All rights reserved.

"Corresponding author at: Center for Cell and Gene Therapy, Baylor College of Medicine, 6621 Fannin Street, MC 3-3320, Houston, Texas 77030, USA. Tel.: +1 832824 6891. gdotti@bcm.edu (G. Dotti).

Publisher's Disclaimer: This is a PDF file of an unedited manuscript that has been accepted for publication. As a service to our customers we are providing this early version of the manuscript. The manuscript will undergo copyediting, typesetting, and review of the resulting proof before it is published in its final citable form. Please note that during the production process errors may be discovered which could affect the content, and all legal disclaimers that apply to the journal pertain.
} 
integrate into the host genome and produce robust expression of the gene in human T cells and their progeny. These gene delivery systems allow rapid manufacturing ( 2 - 3 weeks) of CAR-modified T cells for clinical use ${ }^{5 ;-10}$. Although these vectors have shown a very good safety profile when applied to T lymphocytes, concerns remains related to the potential insertional mutagenesis they have produced in hematopoietic stem cells (HSC) ${ }^{11-13}$. Other reservations of these vectors may reside in their limited cargo capacity and high manufacturing costs. Alternatives to viral vectors build on the delivery of plasmid DNA $^{14 ; 15}$. While the electroporation of expression plasmids has been essentially abandoned by the great majority of investigators due to its inefficiency, an emerging method takes advantage of combining transposone/transposes (Sleeping Beauty ${ }^{14}$ and Piggybac ${ }^{15}$ ), with the convenience of considerably reducing the manufacturing costs and increasing the cargo capacity of the vector, favoring the inclusion of multiple genes. Still, ex vivo cultures required to manufacture CAR-modified $\mathrm{T}$ cells with this technology remain considerably long (4 - 5 weeks) because of the need to enrich the small percentage of CAR-modified T cells. Conversely, increasing evidences suggest that the duration of ex vivo cultures, required to produce sufficient number of CAR-modified cells for adoptive transfer, is particularly relevant. Preclinical models ${ }^{16}$ and data from patients infused with ex vivo expanded tumor infiltrating $\mathrm{T}$ lymphocytes show a direct correlation between short culture conditions and increased in vivo proliferation/survival of these cells after adoptive transfer ${ }^{17}$. Hence it is critical to develop methodologies that enable the generation of large numbers of CARmodified $\mathrm{T}$ cells in a relatively short period of time. Finally, the cytokines employed ex vivo for T-cell expansion appear to affect the in vivo outcome of manufactured CAR-T cells. For instance, the use of gamma-chain cytokines such as IL-7 and IL-15 as opposed to the conventional IL-2 may aid in preserving subsets of T cells with central-memory characteristics, thereby favoring their long-term persistence ${ }^{18}$.

\section{CAR-modified $T$ cells and the role of the costimulation}

T-cell activation requires TCR engagement and co-stimulation provided by professional antigen presenting cells ${ }^{19}$. A multiplicity of sequential T-cell costimulatory receptor-ligands occurs in secondary lymphoid organs. In contrast, tumor cells and the tumor microenvironment are deficient in costimulatory signals but abundant in inhibitory factors, and ultimately induce T-cell anergy, exhaustion or death ${ }^{20}$.

To supply costimulation within the tumor microenvironment, costimulatory signaling domains derived from molecules like CD28 $21 ; 22,4-1 \mathrm{BB}^{23}$ or $\mathrm{OX} 40^{24}$ have been incorporated in tandem into CARs (Fig. 1). This modification is undeniably a key element for the current clinical success of CAR-T-cell therapies in lymphoid malignancies. Side-byside comparison of CARs with or lacking these endodomains clearly outlined the specific role of costimulation in promoting the persistence of CAR-T cells in vivo after adoptive transfer ${ }^{5}$. The costimulation provided by $4-1 \mathrm{BB}$ seems particularly effective ${ }^{7 ; 10}$, although additional and larger studies are needed to establish its potential superiority as compared to the CD28-mediated costimulation and its provision of robust persistence and antitumor effects also in the context of solid tumors, which are particularly abundant in inhibitory mechanisms.

\section{CAR-engraftment in specific T-cell subsets}

The expression of CARs in polyclonal activated $\mathrm{T}$ cells remains the most practical procedure used to rapidly generate large number of these antigen-specific T cells. Recently, interests have been focused on expressing CARs in specific T-cell subsets to either take advantage of the specific biologic properties or tissue tropism of each subset, or to reduce potential side effects associated with the insertion of CARs in otherwise quiescent T-cell subtypes. In this 
regard, CARs have been inserted in $\gamma \delta \mathrm{T}$ lymphocytes ${ }^{25}$, natural killer cells $(\mathrm{NKs})^{26}$, centralmemory T cells ${ }^{27 ; 28}$ and virus-specific cytotoxic T lymphocytes (CTLs) ${ }^{6 ; 29 ; 30}$ and natural killer T cells (NKTs) ${ }^{31} \cdot \gamma \delta$ T lymphocytes may be particularly suitable for applications in patients with epithelial tumors due to their intrinsic tropism to these tissues, while NKs and NKTs may be particularly effective in the context of the allogeneic HSC transplant as they do not induce graft versus host disease. At our institution, we extensively investigated the use of virus-specific CTLs as a platform for CAR engraftment. In particular, we demonstrated in patients with relapsed refractory neuroblastoma that Epstein Barr Virus (EBV)-specific CTLs engrafted with a CAR can persist long term, as they receive physiologic costimulations though their native aßTCRs engaging EBV-epitopes presented by professional antigen presenting cells, while promoting objective tumor regression through the CAR component ${ }^{6}$. Since these cells also lack alloreactivity, we recently extended ths apporch in the allogeneic setting by infusing donor-derived virus-specific CTLs engrafted with a CD19-specific CAR in patients with B-cell derived malignancies relapsed after allogeneic HSC transplant ${ }^{32 ; 33}$.

\section{Toxicities of CAR-modified T cells}

Recent clinical trials have indicated that CAR-T cell-based therapies can be associated with important side effects. An obvious toxicity is related to the lack of discrimination between tumor cells and normal tissues when the selected antigen targeted by CAR-T cells is deliberately a lineage restricted antigen. An obvious example of this type of toxicity is the depletion of the B-cell lineage by CAR-T cells redirected against the CD19 antigen. In fact, in parallel to promoting remarkable antileukemia effects, $\mathrm{T}$ cells directed against this antigen cause profound and durable depletion of normal B cells ${ }^{8-10}$. This expected side effect can be compensated by the infusion of human gamma globulins and may represent an acceptable toxicity in patients with otherwise incurable leukemia.

However, now that the clinical efficacy of these therapies has been proved, the selection of more restricted antigens sounds like a realistic alternative to control the tumor growth while preserving at least part of the normal B-cell compartment ${ }^{22 ; 34 ; 35}$.

Life threatening toxicities due to the concomitant cytotoxic activity of CAR-T cells on normal tissues have been reported in clinical trials targeting the carboxyl-anhydrase-IX $(\mathrm{CAIX})^{36}$ or HER $2^{37}$. CAR-T cells specific for CAIX, an antigen frequently overexpressed in clear cell renal carcinoma, have induced liver toxicity as the same antigen is also expressed by bile duct epithelial cells ${ }^{36}$. Similarly, CAR-T cells specific for HER2 may have target the low level of HER2 expressed in the pulmonary parenchyma or vasculature in an infused patient with lung cancer, causing fatal pulmonary dysfunction ${ }^{37}$. In addition to these toxicities strictly related to the tissue distribution of the antigen, a systemic inflammatory response syndrome (SIRS) or cytokine storm has been reported in patients infused with CAR-T cells ${ }^{7 ; 10}$. This effect is likely attributable to a general perturbation of the immune system and associated with the release of high levels of proinflammatory cytokines, such as TNF-a and IL-6. Although potentially reversible by the prompt administration of blocking antibodies this syndrome remains a major concern for the large scale application of these therapies to non specialized centers.

As we increase the potency and persistence of CAR-T cells it is likely that the inclusion of switch off gene systems will become desirable to rapidly eliminate CAR-T cells in case of severe or life threatening toxicity, or on demand to terminate their effects like to confine the B-cell aplasia associated with CD19-CAR-specific T cells. The inducible caspase9 suicide gene that we developed in our group is quite attractive for this function ${ }^{38 ; 39}$. Indeed, this system induces indeed rapid apoptosis of $\mathrm{T}$ cells, has reduced immunogenicity as the 
sequences are all of human origin and, is selectively activated by an otherwise bioinert small molecule known as chemical inducer of dimerization (CID) ${ }^{39 ; 40 .}$

\section{Conclusion and Future Perspectives}

The objective clinical responses reported in small clinical studies in patients with lymphoid malignancies treated with CAR-modified $\mathrm{T}$ cells have been embraced by a general enthusiasm involving not only the scientific community but also biotech companies interested in help moving these treatments from the academic environment to a broader clinical application. Several steps remain to be refined especially in the simplification of the manufacturing process to extend the application of these technologies, but their effectiveness has been finally incontrovertibly demonstrated.

\section{Acknowledgments}

This work was supported in part by R01 CA142636 National Institutes of Health-NCI, R01CA131027, National Institutes of Health-NCI, W81XWH-10-10425 Department of Defense, Technology/Therapeutic Development Award and a Leukemia and Lymphoma Society Translational Research grant.

\section{References}

1. Eshhar Z, Waks T, Gross G, Schindler DG. Specific activation and targeting of cytotoxic lymphocytes through chimeric single chains consisting of antibody-binding domains and the gamma or zeta subunits of the immunoglobulin and T-cell receptors. Proc Natl Acad Sci USA. 1993; 90:720-724. [PubMed: 8421711]

2. Sadelain M, Brentjens R, Riviere I. The basic principles of chimeric antigen receptor design. Cancer Discov. 2013; 3:388-398. [PubMed: 23550147]

3. Jena B, Dotti G, Cooper LJ. Redirecting T-cell specificity by introducing a tumor-specific chimeric antigen receptor. Blood. 2010; 116:1035-1044. [PubMed: 20439624]

4. Ramos CA, Dotti G. Chimeric antigen receptor (CAR)-engineered lymphocytes for cancer therapy. Expert Opin Biol Ther. 2011; 11:855-873. [PubMed: 21463133]

5. Savoldo B, Ramos CA, Liu E, et al. CD28 costimulation improves expansion and persistence of chimeric antigen receptor-modified T cells in lymphoma patients. J Clin Invest. 2011; 121:18221826. [PubMed: 21540550]

6. Pule MA, Savoldo B, Myers GD, et al. Virus-specific T cells engineered to coexpress tumor-specific receptors: persistence and antitumor activity in individuals with neuroblastoma. Nat Med. 2008; 14:1264-1270. [PubMed: 18978797]

7. Kalos M, Levine BL, Porter DL, et al. T cells with chimeric antigen receptors have potent antitumor effects and can establish memory in patients with advanced leukemia. Sci Transl Med. 2011; 3:95ra73.

8. Brentjens RJ, Davila ML, Riviere I, et al. CD19-targeted T cells rapidly induce molecular remissions in adults with chemotherapy-refractory acute lymphoblastic leukemia. Sci Transl Med. 2013; 5:177ra38.

9. Kochenderfer JN, Wilson WH, Janik JE, et al. Eradication of B-lineage cells and regression of lymphoma in a patient treated with autologous $\mathrm{T}$ cells genetically engineered to recognize CD19. Blood. 2010; 116:4099-4102. [PubMed: 20668228]

10. Grupp SA, Kalos M, Barrett D, et al. Chimeric antigen receptor-modified T cells for acute lymphoid leukemia. N Engl J Med. 2013; 368:1509-1518. [PubMed: 23527958]

11. Bonini C, Grez M, Traversari C, et al. Safety of retroviral gene marking with a truncated NGF receptor. Nat Med. 2003; 9:367-369. [PubMed: 12669036]

12. Bear AS, Morgan RA, Cornetta K, et al. Replication-competent retroviruses in gene-modified T cells used in clinical trials: is it time to revise the testing requirements? Mol Ther. 2012; 20:246249. [PubMed: 22297819] 
13. Hacein-Bey-Abina S, Garrigue A, Wang GP, et al. Insertional oncogenesis in 4 patients after retrovirus-mediated gene therapy of SCID-X1. J Clin Invest. 2008; 118:3132-3142. [PubMed: $18688285]$

14. Singh H, Manuri PR, Olivares S, et al. Redirecting specificity of T-cell populations for CD19 using the Sleeping Beauty system. Cancer Res. 2008; 68:2961-2971. [PubMed: 18413766]

15. Wilson MH, Coates CJ, George AL Jr. PiggyBac transposon-mediated gene transfer in human cells. Mol Ther. 2007; 15:139-145. [PubMed: 17164785]

16. Gattinoni L, Klebanoff CA, Palmer DC, et al. Acquisition of full effector function in vitro paradoxically impairs the in vivo antitumor efficacy of adoptively transferred CD8+ T cells. J Clin Invest. 2005; 115:1616-1626. [PubMed: 15931392]

17. Robbins PF, Dudley ME, Wunderlich J, et al. Cutting edge: persistence of transferred lymphocyte clonotypes correlates with cancer regression in patients receiving cell transfer therapy. J Immunol. 2004; 173:7125-7130. [PubMed: 15585832]

18. Ma A, Koka R, Burkett P. Diverse functions of IL-2, IL-15, and IL-7 in lymphoid homeostasis. Annu Rev Immunol. 2006; 24:657-679. [PubMed: 16551262]

19. Zehn D, King C, Bevan MJ, Palmer E. TCR signaling requirements for activating T cells and for generating memory. Cell Mol Life Sci. 2012; 69:1565-1575. [PubMed: 22527712]

20. Igney FH, Krammer PH. Immune escape of tumors: apoptosis resistance and tumor counterattack. J Leukoc Biol. 2002; 71:907-920. [PubMed: 12050175]

21. Maher J, Brentjens RJ, Gunset G, Riviere I, Sadelain M. Human T-lymphocyte cytotoxicity and proliferation directed by a single chimeric TCRzeta /CD28 receptor. Nat Biotechnol. 2002; 20:7075. [PubMed: 11753365]

22. Vera J, Savoldo B, Vigouroux S, et al. T lymphocytes redirected against the kappa light chain of human immunoglobulin efficiently kill mature B lymphocyte-derived malignant cells. Blood. 2006; 108:3890-3897. [PubMed: 16926291]

23. Imai C, Mihara K, Andreansky M, et al. Chimeric receptors with 4-1BB signaling capacity provoke potent cytotoxicity against acute lymphoblastic leukemia. Leukemia. 2004; 18:676-684. [PubMed: 14961035]

24. Pule MA, Straathof KC, Dotti G, et al. A chimeric T cell antigen receptor that augments cytokine release and supports clonal expansion of primary human T cells. Mol Ther. 2005; 12:933-941. [PubMed: 15979412]

25. Rischer M, Pscherer S, Duwe S, et al. Human gammadelta T cells as mediators of chimaericreceptor redirected anti-tumour immunity. Br J Haematol. 2004; 126:583-592. [PubMed: 15287953]

26. Imai C, Iwamoto $\mathrm{S}$, Campana D. Genetic modification of primary natural killer cells overcomes inhibitory signals and induces specific killing of leukemic cells. Blood. 2005; 106:376-383. [PubMed: 15755898]

27. Berger C, Jensen MC, Lansdorp PM, et al. Adoptive transfer of effector CD8+ T cells derived from central memory cells establishes persistent $\mathrm{T}$ cell memory in primates. J Clin Invest. 2008; 118:294-305. [PubMed: 18060041]

28. Terakura S, Yamamoto TN, Gardner RA, et al. Generation of CD19-chimeric antigen receptor modified CD8+ T cells derived from virus-specific central memory T cells. Blood. 2012; 119:7282. [PubMed: 22031866]

29. Savoldo B, Rooney CM, Di Stasi A, et al. Epstein Barr virus specific cytotoxic T lymphocytes expressing the anti-CD30 zeta $\}$ artificial chimeric T-cell receptor for immunotherapy of Hodgkin disease. Blood. 2007; 110:2620-2630. [PubMed: 17507664]

30. Rossig C, Bollard CM, Nuchtern JG, Rooney CM, Brenner MK. Epstein-Barr virus-specific human T lymphocytes expressing antitumor chimeric T-cell receptors: potential for improved immunotherapy. Blood. 2002; 99:2009-2016. [PubMed: 11877273]

31. Heczey A, Liu D, Courtney AN, et al. NKT Cells as a Novel Platform for Cancer Immunotherapy with Chimeric Antigen Receptors [abstract]. Molecular Therapy. 2013; 21:S5.

32. Cruz R, Micklethwaite P, Savoldo B, et al. Infusion of CD19-Directed and Multivirus Specific Cytotoxic T Lymphocytes After Allogeneic Hematopoietic Stem Cell Transplantation for B Cell Malignancies [abstract]. Blood. 2011; 118 
33. Micklethwaite KP, Savoldo B, Hanley PJ, et al. Derivation of human T lymphocytes from cord blood and peripheral blood with antiviral and antileukemic specificity from a single culture as protection against infection and relapse after stem cell transplantation. Blood. 2010; 115:26952703. [PubMed: 20110422]

34. Giordano Attianese GM, Marin V, Hoyos V, et al. In vitro and in vivo model of a novel immunotherapy approach for chronic lymphocytic leukemia by anti-CD23 chimeric antigen receptor. Blood. 2011; 117:4736-4745. [PubMed: 21406718]

35. Hudecek M, Schmitt TM, Baskar S, et al. The B-cell tumor-associated antigen ROR1 can be targeted with T cells modified to express a ROR1-specific chimeric antigen receptor. Blood. 2010; 116:4532-4541. [PubMed: 20702778]

36. Lamers CH, Sleijfer S, Vulto AG, et al. Treatment of metastatic renal cell carcinoma with autologous T-lymphocytes genetically retargeted against carbonic anhydrase IX: first clinical experience. J Clin Oncol. 2006; 24:e20-e22. [PubMed: 16648493]

37. Morgan RA, Yang JC, Kitano M, et al. Case report of a serious adverse event following the administration of $\mathrm{T}$ cells transduced with a chimeric antigen receptor recognizing ERBB2. Mol Ther. 2010; 18:843-851. [PubMed: 20179677]

38. Straathof KC, Pule MA, Yotnda P, et al. An inducible caspase 9 safety switch for T-cell therapy. Blood. 2005; 105:4247-4254. [PubMed: 15728125]

39. Di Stasi A, Tey SK, Dotti G, et al. Inducible apoptosis as a safety switch for adoptive cell therapy. N Engl J Med. 2011; 365:1673-1683. [PubMed: 22047558]

40. Hoyos V, Savoldo B, Quintarelli C, et al. Engineering CD19-specific T lymphocytes with interleukin-15 and a suicide gene to enhance their anti-lymphoma/leukemia effects and safety. Leukemia. 2010; 24:1160-1170. [PubMed: 20428207] 

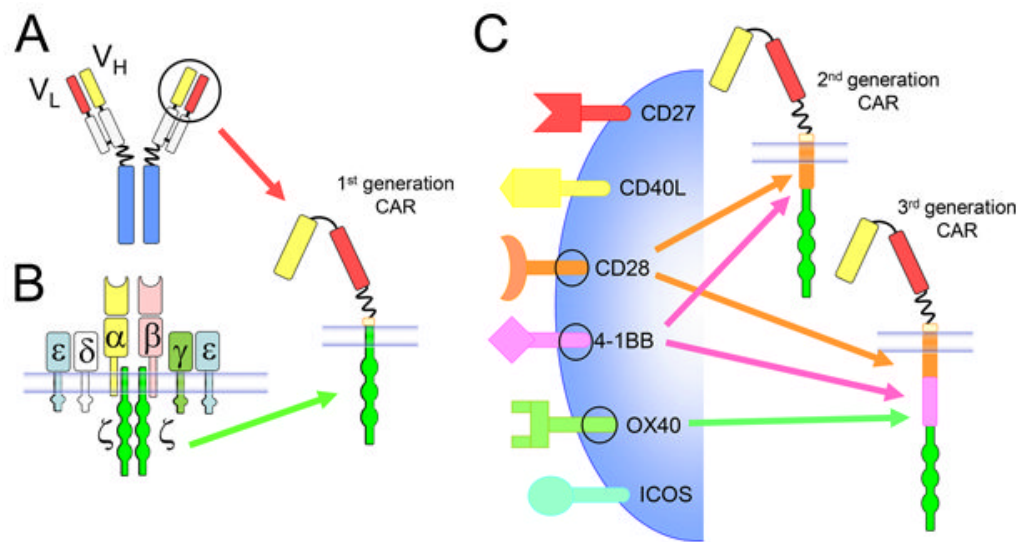

Fig. 1. Chimeric Antigen Receptors (CARs)

CARs are most commonly created by joining the heavy- and light-chain variable regions of a monoclonal antibody (Panel $A$ ) that binds to a specific antigen to the intracellular portion of a T-cell signaling molecule, such as components of the TCR-associated CD3 complex ( $\zeta$ chain) (Panel B). Endodomains of costimulatory molecules such as CD28, 4-1BB and OX40 (Panel $C$ ) are then included in tandem to generate second and third generation CARs (Panel D). 